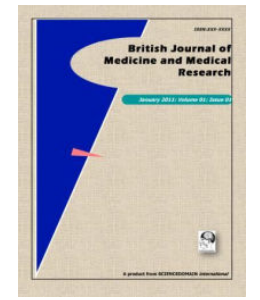

British Journal of Medicine \& Medical Research 2(2): 235-242, 2012

SCIENCEDOMAIN international

www.sciencedomain.org

\title{
Methanol Leaf Extract of Persea americana Protects Rats against Cholesterol-Induced Hyperlipidemia
}

\author{
O. T. Kolawole ${ }^{1 *}$, S. O. Kolawole ${ }^{1}$, A. A. Ayankunle ${ }^{1}$ and I. O. Olaniran ${ }^{1}$ \\ ${ }^{1}$ Department of Pharmacology \& Therapeutics, Ladoke Akintola University of Technology,
} Ogbomoso, Nigeria.

Research Article

Received $12^{\text {th }}$ October 2011

Accepted $20^{\text {th }}$ January 2012

Online Ready $18^{\text {th }}$ March 2012

\section{ABSTRACT}

Aim: To investigate anti-hyperlipidemic activity of methanol leaf extract of Persea americana (MEPA) in cholesterol-induced hyperlipidemic rats.

Methodology: The animals were randomly divided into five groups of 5 rats each. Group1 served as the normal control (NC) and received distilled water. Group 2, the cholesterol-induced hyperlipidemic control (CHOL) was given cholesterol diet $(20 \%$ groundnut oil, $1 \%$ cholesterol and $0.5 \%$ cholic acid mixed with rat pellet) orally. Groups 3 and 4 received oral administration of cholesterol diet and MEPA at a dose of 20 and $40 \mathrm{mg} / \mathrm{kg}$ body weight respectively, while group 5 was treated orally with cholesterol diet and cholestyramine $(0.26 \mathrm{~g} / \mathrm{kg}$ body weight). Cholesterol diet, MEPA and cholestyramine were administered daily for a period of eight weeks.

Results: The changes observed in the plasma levels of total cholesterol (TC), triglycerides (TG), low density lipoprotein (LDL) and high density lipoprotein (HDL) of hyperlipidemic control rats were reversed by MEPA in a dose-dependent manner. At 20 $\mathrm{mg} / \mathrm{kg}$ body weight, MEPA significantly $(\mathrm{p}<0.05)$ reduced TC, TG and LDL plasma levels by $54.2 \%, 46.2 \%$ and $65.6 \%$ respectively, and increased HDL plasma level by $60.0 \%$. At a higher dose of $40 \mathrm{mg} / \mathrm{kg}$, MEPA reduced TC, TG and LDL levels by $60.4 \%$, $69.2 \%$ and $87.5 \%$ respectively while HDL was increased by $80.0 \%$. There was a significant increase of change in body weight of hyperlipidemic rats compared to the change in normal control. MEPA caused a reduction of change in body weight to nearly that of the normal control. MEPA also dose-dependently caused significant reduction $(p<0.05)$ of plasma lipid peroxidation in the rats. The anti-hyperlipidemic effect of MEPA was comparable to that of the standard drug, cholestyramine.

Conclusion: The results of this study showed that Persea americana could be a source 
of good alternative remedy for hyperlipidemia. Further studies are needed to fully understand the mechanism of action of the plant.

Keywords: Persea americana; antihyperlipidemia; antilipoperoxidation; methanol leaf extract; wistar rats.

\section{INTRODUCTION}

Cardiovascular diseases have remained one of the leading causes of death all over the world (Goff et al., 2006). The development of these diseases has been linked to several factors such as high calorie diet intake, lack of exercise, smoking, age, alcohol consumption and genetic disposition (Mitchell et al., 1996). These factors ultimately result in disorders of lipid and lipoprotein metabolism including lipoprotein overproduction and deficiency (Syed et al., 2000).

Causes of hyperlipidemia could be primary or secondary in nature. Primary (genetic) causes are single or multiple gene mutations that result in either overproduction or defective clearance of triglycerides and low density lipoprotein cholesterol, or underproduction and excessive clearance of high density lipoprotein cholesterol (Schaefer and Levy, 1985). Secondary causes include, among others diseases such as diabetes mellitus, chronic liver disease, hypothyroidism and primary biliary cirrhosis. Hyperlipidemia has also been associated with enhanced oxidative stress related to increased lipid peroxidation (Visavadiya and Narasimhacharya, 2007).

Hyperlipidemia itself usually causes no symptoms but it can lead to symptomatic vascular diseases, including coronary artery disease (CAD) and peripheral arterial disease (Gordon et al., 2007). Various approaches have been employed in the treatment of hyperlipidemia. These include lifestyle modification and pharmacotherapy. Among the drugs that are often prescribed are bile acid resins, nicotinic acid, fibrates and the HMG-CoA reductase inhibitors (Rohilla et al., 2011). However, a quest for natural products with anti-hyperlipidemic potential and with minimal or no side effects is on the increase in recent years because of many adverse effects associated with the use of these synthetic medications (Asaolu et al., 2010).

Drug extracts from plant sources such as Allium sativum, Azadirachta indica, Morus alba and Embelia ribes have been reported to possess anti-hyperlipidemic activity in animal models (Lee et al., 2008). Persea americana (Mill.) is another plant that has been used by traditional healers around the world to treat hyperlipidemia, hypertension and other diseases. In Nigeria for example, alcoholic decoction of the leaf is used by traditional healers to treat hyperlipidemia and hypertension in Ibarapa and Oke-ogun area of the country. It is popularly known as avocado. It belongs to the family Lauraceae. Various morphological parts of $P$. americana are widely used in African traditional medicine for the treatment and management and control of a variety of human diseases, including childhood convulsion and epilepsy (Ojewole and Amabeoku, 2006).

Nigerian herbalists use the aqueous seed extract for the management of hypertension (Ozolua et al., 2009). The fruit of Persea americana is eaten in many parts of the world and has been shown to possess medicinal properties. The edible fruit pulp contains up to $33 \%$ oil rich in monounsaturated fatty acids. These are believed to modify the fatty acid content in 
membranes of vital organs, especially the heart (Ortiz et al., 2004). The carotenoid content of Persea americana has been reported to play significant role in reducing cancer risk (Lu et al., 2005). The aqueous leaf extract has also been demonstrated to possess analgesic and anti-inflammatory activities (Adeyemi et al., 2002). Other medicinal properties of Persea americana are wound healing (Nayak et al., 2008) and hepatoprotection (Kawagishi et al., 2001).

Scientific study of hyperlipidemic effect of the leaves of Persea americana is scanty. Information from such study could lead to a more economic and optimal use of the plant in the management of cardiovascular diseases. We therefore investigated the effect of the leaf extract of $P$. americana on cholesterol-induced hyperlipidemic rats.

\section{MATERIALS AND METHODS}

\subsection{Plant Materials}

Persea americana leaves were collected in June, 2011 from Mercyland area in Osogbo, Nigeria. The leaves were identified and authenticated by a botanist in the Department of Botany, University of Ibadan, Nigeria and voucher specimen was deposited in the herbarium of the Department. The leaves were dried under shade for one week. The dry sample was then milled into fine powder in a commercial blender. Two hundred grams $(200 \mathrm{~g})$ portion of the powder sample was extracted in $70 \%$ methanol over a period of three days. The extract was then filtered using clean cotton wool. The filtrate was evaporated and concentrated on a water bath at $40^{\circ} \mathrm{C}$. The yield was $9.7 \% \mathrm{w} / \mathrm{w}$. The solid sample obtained was stored at $4{ }^{\circ} \mathrm{C}$ in a refrigerator until use.

\subsection{Ethical Consideration}

Experimental protocols and procedures used in this study were approved by the Animal Ethics Committee of Ladoke Akintola University of Technology, Ogbomoso, Nigeria. They also conform to the guidelines in the 'Principles of Laboratory Animal Care' $(\mathrm{NIH}, 1985)$.

\subsection{Experimental Animals}

Wistar rats of both sexes weighing between 120 and $150 \mathrm{~g}$ were obtained from the Animal House of the College of Health Sciences, Ladoke Akintola University of Technology, Ogbomoso, Nigeria. The animals were maintained under standard environmental conditions of $50 \pm 10 \%$ relative humidity and $12 \mathrm{~h}$ light and $12 \mathrm{~h}$ dark cycle throughout the experiment. The animals were used after an acclimatization period of five days in the laboratory environment. During acclimatization, they were provided with standard rat pellets and clean drinking water ad libitum.

\subsection{Experimental Design}

Animals were randomly divided into five groups of 5 rats each. Group 1 served as the normal control and received distilled water. Animals in group 2 (hyperlipidemic control) were given cholesterol diet ( $20 \%$ groundnut oil, $1 \%$ cholesterol and $0.5 \%$ cholic acid mixed with their feed). Rats in groups 3 and 4 received methanol extract of Persea americana (MEPA) orally at doses 20 and $40 \mathrm{mg} / \mathrm{kg}$ body weight respectively in addition to administration of cholesterol diet. Animals in group 5 were treated orally with cholestyramine in addition to the 
cholesterol diet. Cholestyramine was given at a dose of $0.26 \mathrm{~g} / \mathrm{kg}$ body weight (Adaramoye et al., 2008). Cholesterol diet, cholestyramine and MEPA were administered daily for a period of eight weeks.

\subsubsection{Sample collection}

At the end of the 8-week treatments, rats were weighed on a digital balance and then sacrificed by cervical dislocation. Blood was collected from the heart into EDTA tubes. Plasma was obtained by centrifugation at $3000 \mathrm{~g}$ for 15 minutes.

\subsubsection{Estimation of lipid profile}

Plasma total cholesterol (TC), triglycerides (TG) and high density lipoprotein cholesterol (HDL) were determined by enzymatic assay method using analytical kits (Biolabo SA, Maizy, France). Low density lipoprotein cholesterol (LDL) was calculated by Friedewald's formula (Friedewald et al., 1972).

\subsubsection{Estimation of lipid peroxidation (LPO)}

Lipid peroxidation was assayed by the method of Walls et al. (1976). This involves measuring the intensity of pink precipitate formed in a reaction between malondialdehyde (MDA), the end-product of lipid peroxidation and thiobarbituric acid (TBA) at $535 \mathrm{~nm}$ spectophotometrically.

\subsubsection{Statistical analysis}

The values were expressed as mean \pm SEM. Statistical analysis was performed by one way analysis of variance (ANOVA) followed by Tukey multiple comparison tests. $\mathrm{P}<0.05$ was considered significant.

\section{RESULTS AND DISCUSSION}

There were significant changes in the plasma levels of total cholesterol, triglycerides, low density lipoprotein and high density lipoprotein of untreated hyperlipidemic rats when compared with normal control. These changes were reversed by MEPA in a dose-dependent manner as shown in table 2 . A dose of $20 \mathrm{mg} / \mathrm{kg}$ MEPA significantly reduced plasma levels of TC, TG and LDL by $54.2 \%, 46.2 \%$ and $65.6 \%$ respectively, and increased the plasma level of HDL by $60 \%$. Likewise, $40 \mathrm{mg} / \mathrm{kg}$ MEPA significantly $(\mathrm{p}<0.05)$ reduced TC, TG and LDL concentrations by $60.4 \%, 69.2 \%$ and $87.5 \%$ respectively, while HDL concentration increased by $80 \%$. The effect of $40 \mathrm{mg} / \mathrm{kg}$ MEPA was comparable to that of cholestyramine, the standard drug. There was a significant difference in the change in weight of hyperlipidemic control rats in comparison with the change in normal control. After treatment with MEPA and cholestyramine, the change in body weight was reduced to near that of the normal control as shown in table 1. Plasma lipid peroxidation of untreated hyperlipidemic rats increased by $41.2 \%$ of the normal control level. However, 20 and $40 \mathrm{mg} / \mathrm{kg}$ of the extract caused reduction of $30.9 \%$ and $36.8 \%$ of the hyperlipidemic control value respectively (Fig. 1). 
Table 1. Effect of MEPA on the body weight of hyperlipidemic rats

\begin{tabular}{llll}
\hline Group ( $\mathbf{n}=5)$ & $\begin{array}{l}\text { Initial body } \\
\text { weight }(\mathbf{g})\end{array}$ & $\begin{array}{l}\text { Final body } \\
\text { weight }(\mathbf{g})\end{array}$ & $\begin{array}{l}\text { Change in } \\
\text { body weight }(\mathbf{g})\end{array}$ \\
\hline $\mathrm{NC}$ & $136.2 \pm 4.8$ & $169.8 \pm 6.3$ & $33.6 \pm 5.1$ \\
$\mathrm{CHOL}$ & $148.5 \pm 5.0$ & $210.4 \pm 7.2^{*}$ & $61.9 \pm 4.5^{*}$ \\
$\mathrm{CHOL}+\mathrm{MEPA}(20 \mathrm{mg} / \mathrm{kg})$ & $123.0 \pm 5.8$ & $168.6 \pm 6.9$ & $45.6 \pm 6.8$ \\
$\mathrm{CHOL}+\mathrm{MEPA}(40 \mathrm{mg} / \mathrm{kg})$ & $134.3 \pm 6.6$ & $170.2 \pm 5.0^{* *}$ & $35.9 \pm 4.2^{* *}$ \\
$\mathrm{CHOL}+\mathrm{CTR}(0.26 \mathrm{~g} / \mathrm{kg})$ & $147.0 \pm 5.4$ & $183.5 \pm 8.3^{* *}$ & $36.5 \pm 8.0^{* *}$
\end{tabular}

NC- Normal control; CHOL-Cholesterol-induced hyperlipidemic control;CTR-Cholestyramine; ${ }^{*} p<0.05$ compared with Normal control; ${ }^{* *} p<0.05$ compared with hyperlipidemic control

Table 2. Effect of MEPA on the lipid profile $(\mathrm{mmol} / \mathrm{L})$ of hyperlipidemic rats

\begin{tabular}{lllll}
\hline Group (n = 5) & TC & TG & LDL & HDL \\
\hline NC & $1.4 \pm 0.6$ & $0.7 \pm 0.3$ & $0.3 \pm 01$ & $0.8 \pm 1.2$ \\
CHOL & $4.8 \pm 1.6^{*}$ & $2.6 \pm 0.2^{*}$ & $3.2 \pm 0.4^{*}$ & $0.5 \pm 0.1^{*}$ \\
CHOL+MEPA $(20 \mathrm{mg} / \mathrm{kg})$ & $2.2 \pm 0.3^{\mathrm{a}}$ & $1.4 \pm 0.1^{\mathrm{a}}$ & $1.1 \pm 0.5^{\mathrm{a}}$ & $0.8 \pm 0.2^{\mathrm{a}}$ \\
CHOL+MEPA $(40 \mathrm{mg} / \mathrm{kg})$ & $1.9 \pm 0.5^{\mathrm{a}}$ & $0.8 \pm 0.3^{\mathrm{a}}$ & $0.4 \pm 0.2^{\mathrm{a}}$ & $0.9 \pm 0.5^{\mathrm{a}}$ \\
CHOL+CTR $(0.26 \mathrm{~g} / \mathrm{kg})$ & $1.6 \pm 0.4^{\mathrm{a}}$ & $0.7 \pm 0.2^{\mathrm{a}}$ & $0.5 \pm 0.1^{\mathrm{a}}$ & $0.9 \pm 0.2^{\mathrm{a}}$ \\
\hline${ }^{*}<0.05$ compared with Normal control; ${ }^{\mathrm{a}} p<0.05$ compared with hyperlipidemic control
\end{tabular}

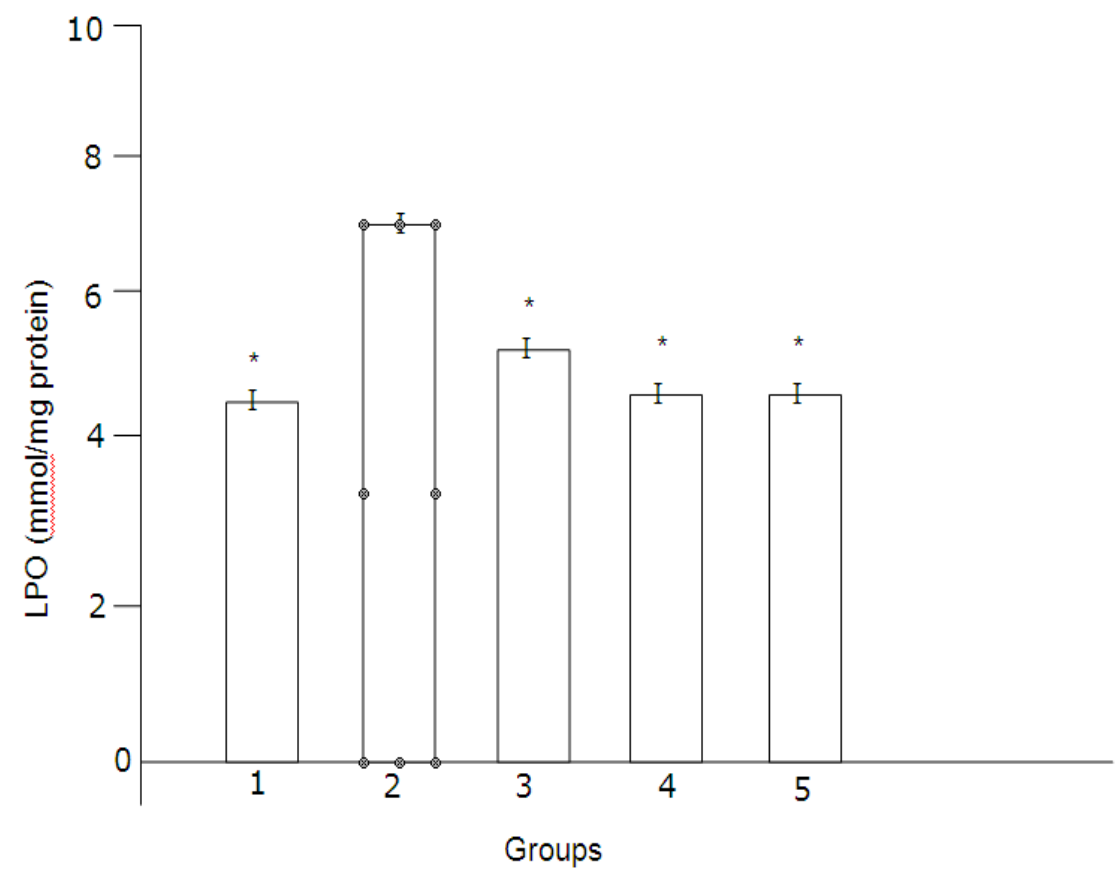

Fig 1. Effect of MEPA on plasma lipid peroxidation in hyperlipidemic rats ${ }^{*} P<0.05$ compared with hyperlipidemic control

Hyperlipidemia is a major risk factor in the pathogenesis of atherosclerosis, a physiologic disorder that affects the coronary, cerebral and peripheral arterial circulation. The 
association between hyperlipidemia and atherosclerosis has been demonstrated in many studies and trials (Gordon et al., 2007). Hyperlipidemia may be manifested by elevation of total cholesterol, low density lipoprotein and triglycerides concentrations and a reduction in high density lipoprotein concentration. It has also been shown that reducing plasma level of LDL cholesterol sharply reduced the risk of coronary heart disease (Superko and Krauss, 1994).

Furthermore, high plasma levels of HDL cholesterol are associated with lower risk of coronary heart disease and it is widely believed that HDL protects against atherosclerosis by facilitating reverse cholesterol transport (Van et al., 2009). In the present study, methanol extract of Persea americana (MEPA) significantly reduced plasma concentrations of total cholesterol (TC), low density lipoprotein LDL) and triglycerides (TG) in cholesterol-induced hyperlipidemic rats. MEPA also caused a significant increase in the HDL concentration. The anti-hyperlipidemic effect of MEPA was also reflected in the change in body weight of the animals. The excessive weight gain observed in the hyperlipidemic rats was brought down to near normal by MEPA. Oxidative stress plays a major role in the pathogenesis of atherosclerosis (Adaramoye et al., 2005). In this study, there was a significant increase in lipid peroxidation in the hyperlipidemic animals. Increased lipid peroxidation would lead to the generation of harmful free radicals which impair membrane function and ultimately results in microvascular and macrovascular complications (Virella-Lopes and Virella, 2003). The increase in lipid peroxidation observed in hyperlipidemic rats was reversed to near normal level by MEPA and cholestyramine. This suggests that MEPA may possess antioxidant effects. This is most likely the case because isolation of bioactive phytoconstituents from the leaves of Persea americana has produced compounds with antioxidant properties such as luteolin, rutin, quercetin and apigenin (Owolabi et al., 2010).

There are other possible mechanisms by which MEPA lowers serum lipid. It could reduce the biosynthesis of cholesterol by inhibiting the activity of 3-hydroxy-3-methylglutaryl coenzyme-A reductase (HMG-CoA reductase), the key enzyme in cholesterol synthesis. MEPA could also act by increasing the activity of lecithin-cholesterol acyl transferase (LCAT). This enzyme plays an important role in incorporating free cholesterol into HDL (Geetha et al., 2011). This will promote reverse cholesterol transport and competitively inhibits the uptake of LDL by endothelia cells. Since MEPA increased the plasma concentration of HDL, these and other beneficial roles of HDL would be enhanced.

\section{CONCLUSION}

At present the exact mechanism of action of MEPA is not fully understood. Further studies in this direction are needed for possible isolation and structural elucidation of the antihyperlipidemic component of Persea americana. In the meantime, this study has demonstrated that Persea americana may be a source of good remedy against hyperlipidemia.

\section{COMPETING INTERESTS}

Authors have declared that no competing interests exist. 


\section{REFERENCES}

Adaramoye, O.A., Nwaneri, V.O., Anyanwu, K.C, Farombi, E.O., Emerole, G.O. (2005). Possible anti-atherogenic effect of kolaviron (a Garcinia kola seed extract) in hypercholesterolaemic rats. Clin Exp Pharmacol Physiol., 32, 40-46.

Adaramoye, O.A., Akintayo, O., Achem, J., Fafunso, M.A. (2008). Lipid-lowering effects of methanolic extract of Vernonia amygdalina leaves in rats fed on high cholesterol diet. Vasc Health and Risk Manag, 4(1), 235-241.

Adeyemi, O.O., Okpo, S.O., Ogunti, O.O. (2002). Analgesic and anti-inflammatory effects of the aqueous extract of leaves of Persea americana (Lauraceae). Fitoterapia, 73, 375380.

Asaolu, M.F., Samuel, S., Oyeyemi, A.O., Bukola, T. (2010). Hypolipidemic effects of methanolic extract of Persea americana seeds in hypercholesterolaemic rats. Journal of Medicine and Medical Science, 1(4), 126-128.

Friedewald, W.T., Levy, R.I., Fredickson, D.S. (1972). Estimation of the concentration of low density lipoprotein cholesterol in plasma without the use of preparative ultracentrifugation. Clin Chem., 18, 499-502.

Geetha, G., Kalavalarasariel, G.P., Sankar, V. (2011). Antidiabetic effect of Achyranthes rubrofusca leaf extracts on alloxan induced diabetic rats. Pak. J. Pharm. Sci., 24(2), 193-199.

Goff, D.C., Bertoni, A.G., Kramer, H., Bonds, D., Blumenthal, R.S., Tsai, M.Y., Psaty, B.M. (2006). Dyslipidemia prevalence, treatment and control in the multi-ethnic study of atherosclerosis (MESA): gender, ethnicity, and coronary artery calcium. Circulation, 113(5), 647-656.

Gordon, T., Castelli, W.P., Hjortland, M.C., Kannel, W.B., Dawber, T.R. (1997). High density lipoprotein as a protective factor against coronary heart disease: The Framingham study. Am J Med., 62(5), 705-714.

Kawagishi, H., Fukumoto, Y., Hatakeyama, M., He, P., Arimoto, H., Matsuzawa, T., Arimoto, Y., Suganuma, H., Inakuma, T., Sugiyama, K. (2001). Liver injury suppressing compounds from avocado (Persea americana ). J. Agic Food Chem., 49(5), 2215-21.

Lee, J., Chae, K., Ha, J., Park, B.Y., Lee, H.S., Jeong, S., Kim, M.Y., Yoon, M. (2008). Regulation of obesity and lipid disorders by herbal extracts from Morus alba, Melissa officinalis and Artemisia capillaris in high fat diet-induced obese mice. J Ethnopharmacol, 115(2), 263-270.

Lu, Q.Y., Arteaga, J.R., Zhang, Q., Huerta, S., Go, V.L., Heber, D. (2005). Inhibition of prostate cancer cell growth by an avocado extract: role of lipid-soluble bioactive substances. J Nutr Biochem, 16(1), 23-30.

Mitchell, B.D., Kammerer, C.M., Blangero, J., Mahanev, M.C., Rainwater, D.L., Dyke, B., Hixson, J.E., Henkel, R.D., Sharp, R.M., Comuzzie, A.G., VandeBerg, J.L., Stern, M.P., MacCluer, J.W. (1996). Genetic and environmental contributions to cardiovascular risk factors in Mexican Americans. The San Antonio Family Heart Study. Circulation, 94, 2159-2170.

Nayak, B.S., Raju, S.S., Chalapathi Rao, A.V. (2008). Wound healing activity of Persea americana (avocado) fruit: a preclinical study on rats. J Wound Care, 17(3), 123-126.

$\mathrm{NIH}$. (1985). Guide for the care and use of laboratory animals. DHHS, PHS, NIH Publication No. 85-23 (1985 Revised).

Ojewole, J.A.O., Amabeoku, G.J. (2006). Anticonvulsant effect of Persea americana Mill (Lauraceae) (Avocado) leaf aqueous extract in mice. Phytotherapy Research, 20(8), 696-700. 
Ortiz, M.A., Dorantes, A.L., Gallndez, M.J., Cardenas, S.E. (2004). Effect of a novel oil extraction method on avocado (Persea americana) pulp microstructure. Plant Foods Hum Nutr., 59(1), 11-14.

Owolabi, M.A., Coker, H.A.B., Jaja, S.I. (2010). Bioactivity of the phytoconstituents of the leaves of Persea americana. J Med Plant Res., 4(12), 1130-1135.

Ozolua, R.I., Anaka, O.N., Okpo, S.O., Idogun, S.E. (2009). Acute and subacute toxicological assessment of the aqueous seed extract of Persea americana Mill (Lauraceae) in rats. Afr. J Tradit Complement Altern Med., 6(4), 573-578.

Rohilla, A., Rohilla, S., Singh, G., Kumar, A., Khan, M.U. (2011). Atorvastatin pleiotropism: Role in cardioprotection. Int J Pharmacute Biol Arch, 2(3), 813-818.

Schaefer, E.J., Levy, R.I. (1985). Pathogenesis and management of lipoprotein disorders. New Engl J Med., 312(20), 1300-10.

Superko, H.R., Krauss, R.M. (1994). Coronary artery disease regression. Convincing evidence for the benefit of aggressive lipoprotein management. Circulation, 90, 105669.

Syed, M., Mark, C., John, F.D. (2000). Management of dyslipidemia in adults. The Am Fam Physi, 1, 1-12.

Van, E.C., Lievens, J., Jacobs, F., Feng, Y., Snoeys, J., Geest, B.A. (2009). Apolipoprotein A-I and lecithin cholesterol acyltransferase transfer induce cholesterol unloading. Gene therapy, 16, 757-765.

Virella -Lopes, M.F.L., Virella, G. (2003). The role of immune and inflammatory processes in the development of macrovascular disease in diabetes. Frontiers in Biosc., 8, 750-768.

Visavadiya, N.P., Narasimhacharya, A.V. (2007). Ameliorative effect of Chlorophytum borivilianum root on lipid metabolism in hyperlipidemic rats. Clin Exp Pharmacol Physiol, 34, 244-249.

Walls, R., Kumar, K.S., Hochstein, P. (1976). Aging of human erythrocytes: Differential sensitivity of young and old erythrocytes to hemolysis induced by peroxide in the presence thyroxine. Arch Biochem Biophys, 174(2), 463-468.

(C) 2012 Kolawole et al.; This is an Open Access article distributed under the terms of the Creative Commons Attribution License (http://creativecommons.org/licenses/by/3.0), which permits unrestricted use, distribution, and reproduction in any medium, provided the original work is properly cited. 